\title{
Multifocal Chest Wall Hamartoma: A Rare Congenital Anomaly
}

\author{
Abhilasha Jain 1*, Sharad Jain², Jayesh Patel1, Anil Vasoya1, Swati Gaba1 \\ ${ }^{1}$ Department of Radiodiagnosis and Imaging, B.J. Medical College, Civil Hospital, Ahmedabad, India \\ ${ }^{2}$ Department of Cardiology, U.N. Mehta Heart Institute, Ahmedabad, India \\ Email: ^abhilashasjain@gmail.com, drsharadrjain@gmail.com, drjayeshmpatel@gmail.com, vasoya_anil90@yahoo.co.in, \\ swati_gaba90@yahoo.com
}

How to cite this paper: Jain, A., Jain, S., Patel, J., Vasoya, A. and Gaba, S. (2017) Multifocal Chest Wall Hamartoma: A Rare Congenital Anomaly. Open Journal of Radiology, 7, 292-297.

https://doi.org/10.4236/ojrad.2017.74031

Received: July 3, 2017

Accepted: December 23, 2017

Published: December 26, 2017

Copyright $\odot 2017$ by authors and Scientific Research Publishing Inc. This work is licensed under the Creative Commons Attribution International License (CC BY 4.0).

http://creativecommons.org/licenses/by/4.0/

\begin{abstract}
Chest wall hamartoma is a very rare tumour with benign course and distinct clinical, radiological, and histopathological characteristics. The lesion develops during foetal life and is present at or shortly after birth. It should be kept in differential diagnosis of complex chest wall masses diagnosed during antenatal ultrasound. CT thorax is useful for appreciation of detailed anatomy, characterization of the congenital abnormality and for surgical planning. Histopathology is used for the confirmation. Accurate diagnosis of mesenchymal hamartoma is important since many chest wall masses in children are malignant. We report a rare case of multifocal chest wall hamartoma in an infant who presented with multiple bilateral complex chest wall masses in which characteristic radiological and histopathological features led to the diagnosis of hamartoma, which was successfully treated with surgery.
\end{abstract}

\section{Keywords}

Congenital, Hamartoma, Radiology, Surgery, Neoplasms

\section{Introduction}

Mesenchymal hamartoma of the chest wall is a rare congenital lesion of infancy and childhood [1] [2]. This extremely rare benign entity is often misdiagnosed as malignancy [3]. Macroscopically, the tumors are generally well characterized, lobulated and tan to reddish in color. Such lesions are cluster of varying admixture of mature and immature hyaline cartilage that has features resembling growth plate cartilage, fascicles of spindle cells, woven bone and hemorrhagic cysts secondary to aneurysmal bone cyst formation [1] [3]. Many lesions arise from ribs. Some can have multifocal disease. We emphasize the role of antenatal 
ultrasound in suspicion of diagnosis and cross sectional imaging in diagnosis and surgical planning.

\section{Case Report}

A month old female infant presented with chest wall swelling, deformity, cough and breathing difficulty. At 23 weeks of gestation the same foetus was diagnosed on routine antenatal ultrasound having a complex mass in left hemi thorax (Figure 1). Differential diagnosis of teratoma, adenomatoid malformation or complex chest wall mass was kept.

Laboratory investigations revealed mild anaemia and mildly altered liver function tests. The differential counts were normal. She was referred to the Department of Radio Diagnosis and Imaging for further investigations.

Chest radiograph revealed multiple expansile lesions arising from contiguous ribs causing narrowing and compromise of thoracic cavity (Figure 2(a)). The lesions show heterogeneous appearance with areas of ground glass density and foci of speckled calcification.

Plain and contrast enhanced CT of thorax was performed. Coronal and sagittal reformat and 3D reconstruction images were obtained (Figure 3(a) \& Figure $4(\mathrm{a})$ ). It revealed a large, heterogeneous expansile rib lesions arising from left $4^{\text {th }}$ and $5^{\text {th }}$ ribs with large intrathoracic component resulting in compression of left lung. There are widening of $4^{\text {th }}$ and $5^{\text {th }}$ intercostal spaces and shift of mediastinum towards right side. Another lesion was noted arising from anterior ends of $3^{\text {rd }}$ to $5^{\text {th }}$ ribs. Similar characteristic lesions of small sizes were noted in transverse process of C7 vertebra, posterior ends of left $1^{\text {st }}$ and $3^{\text {rd }}$ ribs and right $1^{\text {st }}$ rib. Few lesions caused gross expansion and cortical thinning forming large masses with large intrathoracic components severely compromising the thoracic cavity and causing chest wall deformity. The matrix of the lesion showed insignificantly enhanced soft tissue attenuation, low attenuation cystic areas and chondroid mineralization.

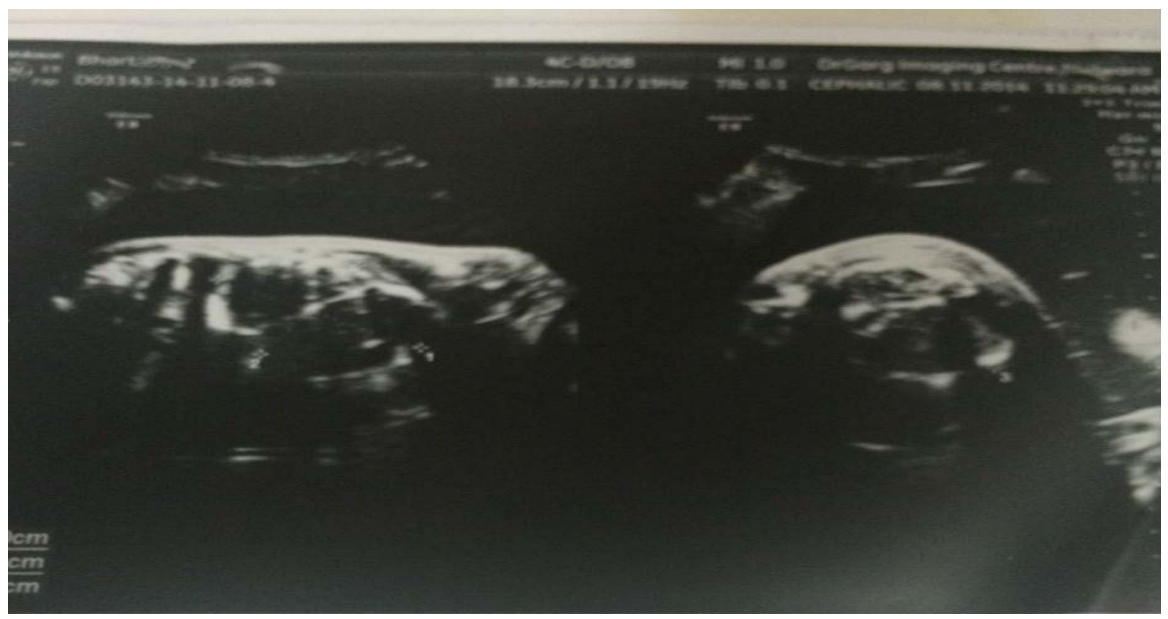

Figure 1. Antenatal ultrasound at 22 week gestation revealed complex chest wall mass with large intrathoracic component. 


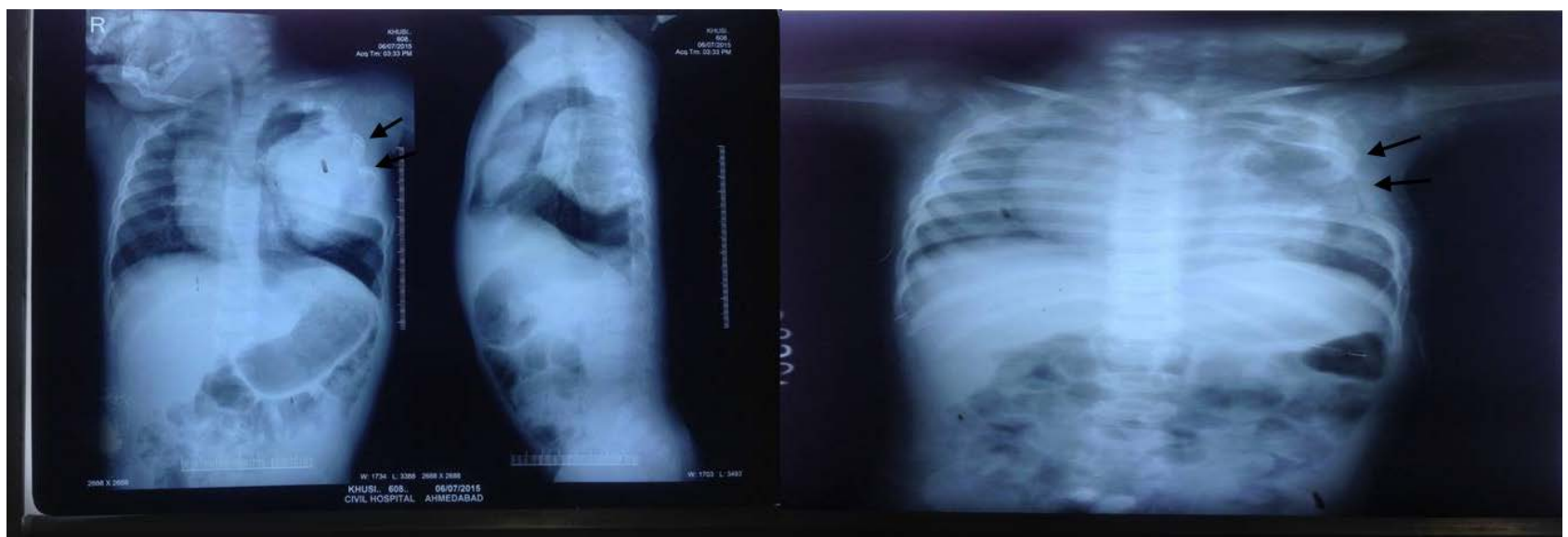

(a)

(b)

Figure 2. (a) Chest frontal and lateral radiograph revealed expansile lesions arising from multiple ribs; (b) Post-operative radiograph.

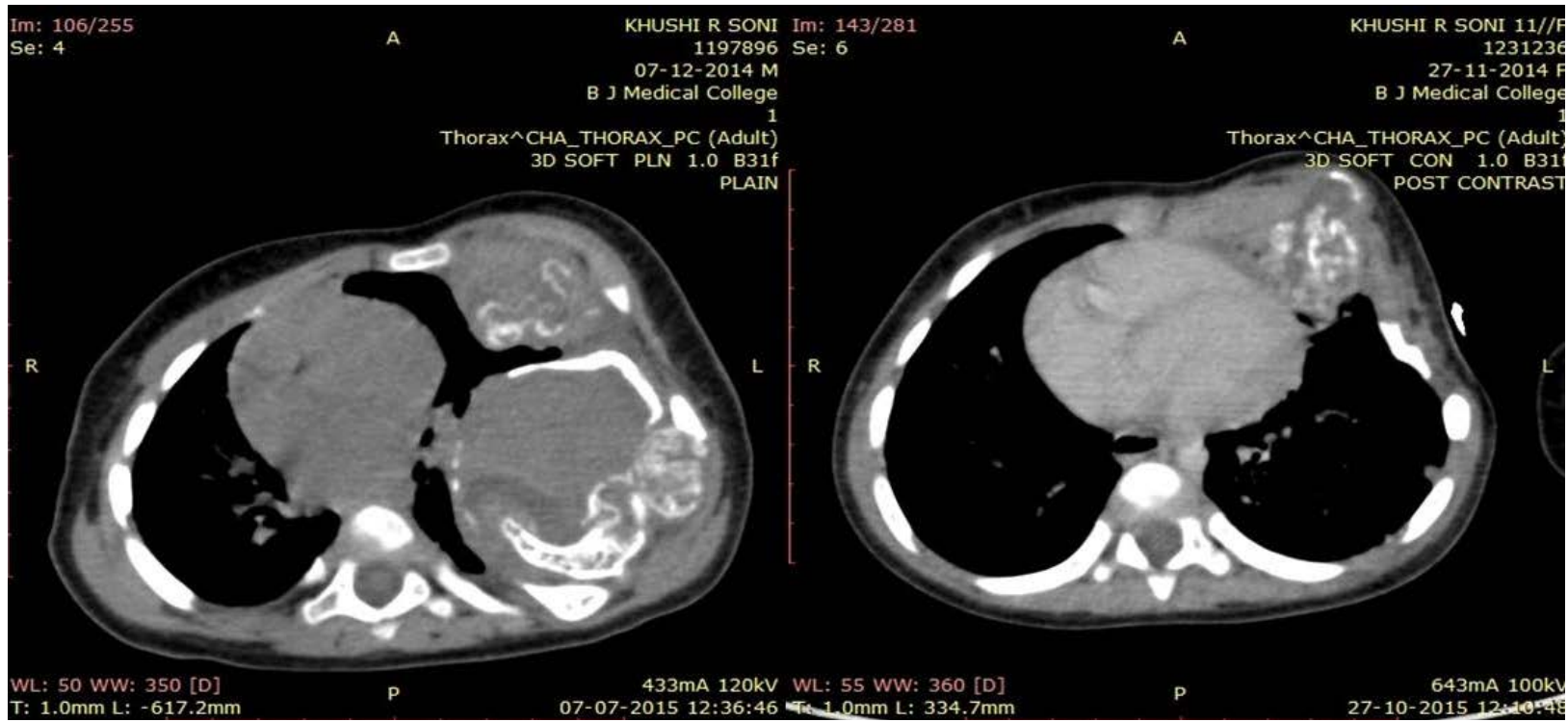

(a)

(b)

Figure 3. (a) CECT revealed multiple large, non-enhancing, heterogeneous expansile rib lesions arising from left $4^{\text {th }}$ and $5^{\text {th }}$ ribs with large intrathoracic component resulting in compression of left lung and opposite shift of mediastinum; (b) Post operative follow-up CECT revealed no recurrence and no change in size and appearance of unresected lesion. There is relieve of lung compression and mediastinal shift.

Based on imaging findings, differential diagnosis of multiple fibrous dysplasia or mesenchymal hamartomas was considered.

Histopathology revealed that the sections chiefly consisted of spindle shaped fibroblast admixed with cartilaginous and bony tissue with evidence of endochondral ossification, suggestive of chondro mesenchymal hamartoma (Figure 5).

Surgical excision of the large lesions is planned based on imaging characteristics and respiratory symptoms. Excision of left $4^{\text {th }}$ and $5^{\text {th }}$ ribs was performed which was associated with large masses. Surgical excision and biopsy of largest 


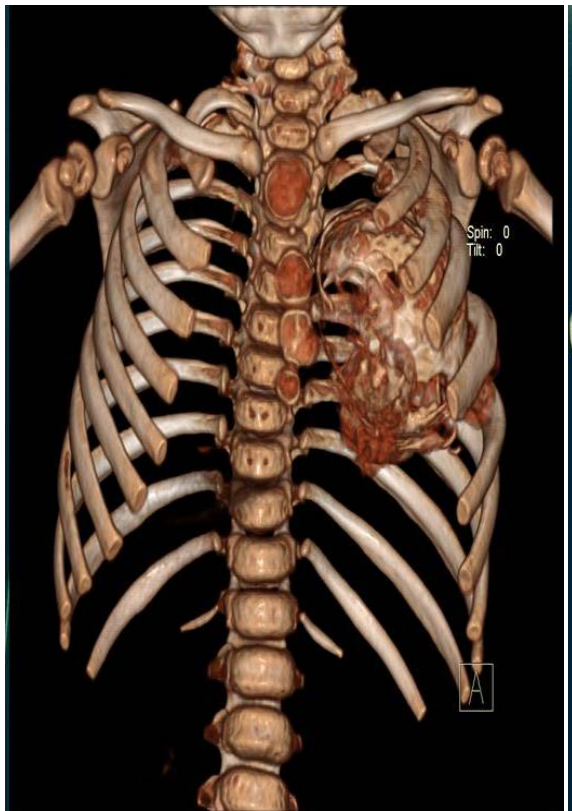

(a)

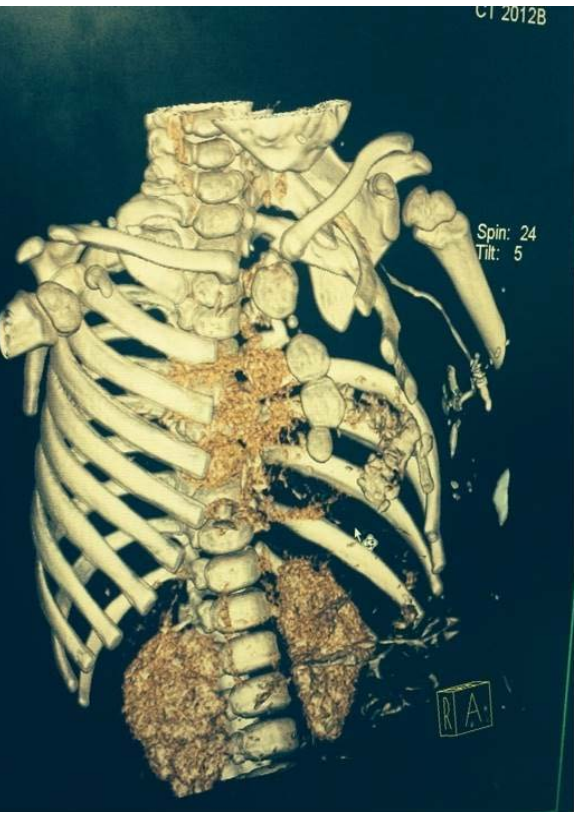

(b)

Figure 4. (a) Pre-operative CT 3D reconstruction image; (b) Post-operative CT 3D reconstruction images.

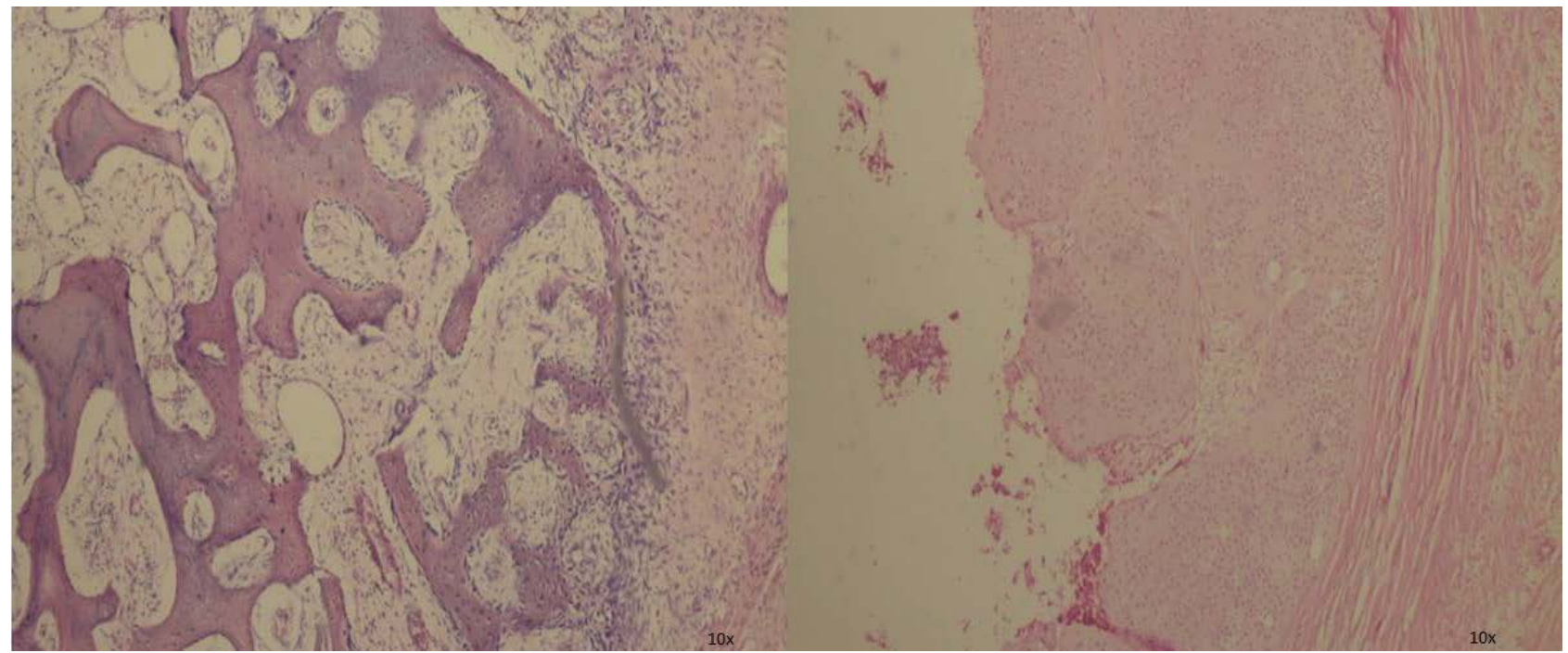

(a)

(b)

Figure 5. Histopathology revealed that the sections chiefly consisted of spindle shaped fibroblast admixed with cartilaginous and bony tissue with evidence of endochondral ossification.

lesion revealed a grossly well encapsulated greyish brown nodular hard tissue structure attached to the ribs. The cut surface was partly solid partly cystic, whitish areas (cartilage) with haemorrhagic areas were seen. The surgery was successful. At 3-month and 6-month follow up, the patient was asymptomatic and had not experienced any episodes of respiratory symptoms. The lesions which were excised did not show recurrence and the lesions which were left does not show any increase in size (Figure 2(b), Figure 3(b) \& Figure 4(b)). 


\section{Discussion}

Mesenchymal hamartoma, the name coined by McLeod and Dahlin, as it is an abnormal proliferation of normal skeletal elements. It is a very rare benign bony lesion, which usually arise from ribs and affect contiguous ribs [4] [5]. In our case, there are bilateral and multifocal lesions, which is a very rare occurrence. It causes focal/ multifocal expansion, morphological distortion and can present as small to large masses with extraosseous component [6]. It usually causes symptoms due to its large size with resultant compressive symptoms over lung and mediastinum and chest wall deformity [5] [7]. Our patient presented with chest wall deformity, cough and respiratory distress soon after birth.

In our case, a complex chest mass was detected during routine antenatal ultrasound at $22^{\text {nd }}$ week and differential diagnosis of teratoma, adenomatoid malformation or chest wall mass was kept. Mesenchymal hamartoma was not suspected because of unawareness of the condition. Retrospective reviewing of sonographic images revealed its characteristic sonographic features of being highly echogenic mass with areas as echogenic as bone which favours its bony origin as against other congenital pulmonary malformation which are not as echogenic as bone [4]. Recognition of congenital malformation during antenatal ultrasound screening is necessary for planning and management of perinatal course.

On imaging mesenchymal hamartoma appears very aggressive specially if multiple and large as in our case but close look reveals ground glass density, speckled calcification, large expansile lesions with cortical destruction, morphological distortion and large extra pleural component which cause compression over lungs and mediastinum and hence the symptoms of respiratory distress [5]. CT scan is helpful in detection of exact number and extent of the lesions and better evaluates the intrathoracic component and status of lung. The lesions show no significant enhancement as against malignant tumours of chest wall. Histologically, the tumour is composed of islands of hyaline cartilage intermixed with mesenchymal stroma and haemorrhagic cyst, osteoclastic type giant cells and areas of endochondral ossification [5]. The typical histopathological features of mesenchymal hamartoma correlate well with radiologic findings [7]. The non-enhancing solid component with areas of calcification on CT corresponds to areas of primitive mesenchymal proliferation and chondroid islands and cystic areas correspond with aneurysmal bone cyst [8] [9].

Accurate diagnosis and distinction of this benign entity from malignant masses encountered at this age is very important for management. Ewings sarcoma and PNET can present with large chest wall masses however rib destruction, sclerosis enhancement, absence of haemorrhagic cysts and presence of abundant round cells favours malignant round cell tumours [9].

Fibrous dysplasia, Langerhans cell histiocytosis, and haemangioma are the common benign lesions affecting ribs, but are uncommon in new-borns [7]. Thus, in a new-borns, a chest wall mass especially if multifocal, with prominent haemorrhagic cystic (secondary $\mathrm{ABC}$ ) components and mineralized elements are 
highly suggestive of mesenchymal hamartoma.

\section{Teaching Points}

- Multifocal congenital hamartomas are very rare.

- They should be suspected in antenatal ultrasound when complex chest wall masses are detected, especially if multifocal.

- The imaging characteristics reflect the histopathological diagnosis.

- It's correct diagnosis is important as surgical resection is curative.

\section{Disclosures}

The authors declare that no conflict of interest exists.

\section{Authors' Contributions}

Abhilasha Jain-Case processing; Sharad Jain-Manuscript preparation and final review; Jayesh Patel-Literature search; Anil Vasoya-Literature search; Swati Gaba-Manuscript drafting.

\section{References}

[1] Cohen, M.C., Drut, R., Garcia, C. and Kaschula, R.O. (1992) Mesenchymal Hamartoma of the Chest Wall: A Cooperative Study with Review of the Literature. Pediatric Pathology, 12, 525-534. https://doi.org/10.3109/15513819209024202

[2] Taweevisit, M., Trinavarat, P. and Thorner, P.S. (2014) Aspiration Cytology of Mesenchymal Hamartoma of the Chest Wall: A Case Report and Literature Review. Diagnostic Cytopathology, 42, 890-894. https://doi.org/10.1002/dc.23072

[3] Li, R., Kelly. D. and Siegal, G.P. (2012) Bilateral Mesenchymal Hamartoma of the Chest Wall in an Infant boy. Fetal and Pediatric Pathology, 31, 415-422. https://doi.org/10.3109/15513815.2012.659412

[4] Brar, M., Cubberley, D., Baty, B. and Branch, D. (1988) Chest Wall Hamartoma in a Fetus. Journal of Ultrasound in Medicine, 7, 217-220. https://doi.org/10.7863/jum.1988.7.4.217

[5] Mahapatar, S., Kar, A., Bhuyan, P., Biswal, P., Das, U. and Dehury, P. (2013) Cytohistomorphological Identification of Congenital Bilateral Mesenchymal Hamartoma of Chest Wall. Journal of Solid Tumors, 3, 7. https://doi.org/10.5430/jst.v3n5p7

[6] Ayala, A.G., Ro, J.Y., Bolio-Solis, A., Hernandez-Batres, F., Eftekhari, F. and Edeiken, J. (1993) Mesenchymal Hamartoma of the Chest Wall in Infants and Children: A Clinicopathological Study of Five Patients. Skeletal Radiology, 22, 569-576. https://doi.org/10.1007/BF00197137

[7] Kim, J.Y., Jung, W.H., Yoon, C.S., et al. (2000) Mesenchymal Hamartomas of the Chest Wall in Infancy: Radiologic and Pathologic Correlation. Yonsei Medical Journal, 41, 615-622. https://doi.org/10.3349/ymj.2000.41.5.615

[8] Groom, K.R., Murphey, M.D., Howard, L.M., Lonergan, G.J., Rosado-de-Christenson, M.L. and Torop, A.H. (2002) Mesenchymal Hamartoma of the Chest Wall: Radiologic Manifestations with Emphasis on Cross-Sectional Imaging and Histopathologic Comparison 1. Radiology, 222, 205-211. https://doi.org/10.1148/radiol.2221010522

[9] Herman, T. and Siegel, M. (2009) Chest Wall Mesenchymal Hamartoma. Journal of Perinatology, 29, 462-463. https://doi.org/10.1038/jp.2008.206 